\title{
Integrated Surface-Subsurface Modeling of Fuxianhu Lake Catchment, Southwest China
}

\author{
Qi Zhang • Adrian D. Werner
}

Published online: 8 August 2009

(C) Springer Science+Business Media B.V. 2009

\section{Erratum to: Water Resour Manage DOI 10.1007/s11269-008-9377-y}

The authors found that the following are unfortunate omissions:

(1) Figure 3 caption should read "Comparison of WATLAC with other models for the V-catchment problem (CD critical depth boundary, ZDG zero depth gradient boundary) (Zhang and Li 2009; reproduced with permission of the copyright holder)".

(2) Figure 4 caption should read "Comparison of WATLAC with MODHMS for sensitivity to various parameters for the conjunctive surface/subsurface flow problem (BC base case, LWT lower water table, LP lower porosity) (Zhang and Li 2009; reproduced with permission of the copyright holder)".

(3) The following statement should be added after the first sentence under section 4 Model Verification:

"The following approach to testing WATLAC closely follows that of Zhang and Li (2009)."

(4) A reference should be added as: Zhang Q, Li L (2009) Development and application of an integrated surface runoff and groundwater flow model for a catchment of Lake Taihu watershed, China. Quat Int. doi:10.1016/j.quaint. 2008.10.015.

The online version of the original article can be found at http://dx.doi.org/10.1007/s11269-008-9377-y.

Q. Zhang $(\varangle)$

State Key Laboratory of Lake Science and Environment, Nanjing Institute of Geography and Limnology, Chinese Academy of Sciences, 73 East Beijing Road, Nanjing 210008, China e-mail: qzhang@niglas.ac.cn

A. D. Werner

School of Chemistry, Physics and Earth Sciences, Flinders University, GPO Box 2100, Adelaide, SA 5001, Australia 